\title{
An die Abonnenten der Zeitschrift für induktive Abstammungs- und Vererbungslehre
}

Die Literaturlisten der Zeitschrift nehmen von Jahr zu Jahr an Umfang zu. Die Literaturzusammenstellungen gliedern sich in zwei Abteilungen, für das rezente und das fossile Material. Ich glaube, daB bei der Zusammensetzung des Abonnentenkreises unserer Zeitschrift die Abteilung B: paläontologische Literatur wesentlich eingeschränkt oder vielleicht ganz ausgelassen werden kann. Ich denke, daß eine Auswahl derjenigen paläontologischen Literatur, welche dem Interessengebiet der Zeitschrift naheliegt, für die Zukunft genügt, während die Redaktion bestrebt sein wird, die gesamte Literatur, die wirklich dem Interessenkreis entspricht, möglichst vollständig und rasch zu bringen.

Ich bitte bis längstens 14 Tage nach dem Erscheinen dieses Heftes um Mitteilung an die Redaktion mit einer Stellungnahme zu dieser Frage.

Fr. v. Wettstein

Redaktion der Zeitschrift für indukt. Abstammungs- u. Vererbungslehre 